ANNA GRANDORI, MARCO FURLOTTI

\title{
FACIO UT FACIAS
}

\section{ASSOCIATIONAL CONTRACTS AND INNOVATION}

Forthcoming in International Studies of Management and Organization 39 (4) WINTER 09/10.

\begin{abstract}
This exploratory study takes a look at the puzzle of what type of contracts are suitable for governing innovation, with particular attention to inter-firm networks. It employs a conceptual framework that integrates organizational theory of formal coordination with economic perspectives on contracting, and innovate previous analyses in two ways: developing an assessment of alternative contractual forms in terms of knowledge governance and not only in terms of conflict resolution; analyzing contracts according to the intensity at which they incorporate not only market-like mechanisms, but also hierarchical and bureaucratic mechanisms, and a usually neglected array of associational and democratic mechanisms, as related to the level of uncertainty and innovation. A new type of 'associational' and 'constitutional' contract, resource-based rather than action-based, is singled out as particularly fit to the governance of innovation. The framework is empirically applied to content-analyze the written agreements regulating inter-firm alliances for innovation in a comparative case study approach.
\end{abstract}

Anna Grandori (anna.grandori@,unibocconi.it), Marco Furlotti (marco.furlotti@unibocconi.it), Crora, Bocconi University, Via Sarfatti 25 - 20136 Milano, Italia.

The generation of innovation typically rests on the discovery of new combinations of resources and activities, hence, of tasks and cooperation patterns that cannot be conceived and described ex-ante. This circumstance is seen as problematic, especially in economics, as it is supposed to generate 'contract incompleteness'. In fact, the now prevailing economic view of contracts under uncertainty, is that in those conditions contracts are 'incomplete', for the cost of writing and 
enforcing 'complete descriptions' of tasks and actions, or for the impossibility of foreseeing all relevant contingencies (Williamson 1975; Hart 1988; Tirole 1999).

In organizational economics two types of solutions to this problem are envisaged: the design of optimally incomplete contracts (e.g. Croker and Reynolds 1993), and the resort to 'relational' and extra-contractual governance (e.g. Macauley 1993). In the first section we point out to some limitations of these two solutions, if applied to the governance of innovation). In the second section we integrate some relevant contributions from constitutional economics and organization theory into the argument, in order to respond to the research question of whether a formal and enforceable, but flexible and open contract, capable of locking in resources in an 'ongoing cooperation' without unduly constraining behaviors can be devised. The third Section shows that these 'associational contracts' do exist and are used in practice, by considering available empirical studies about the content of contracts regulating innovative ventures and by presenting a detailed documental analysis of contractual agreements in the highly innovative context of biotechnology alliances. The final section summarizes our results.

\section{Limitations of optimally incomplete contracts and of relational contracts for innovation}

Scholars in the field of economics of contracts have paid major attention to the solution of conflict of interests under conditions of low substitutability of partners and asset specificity and much less consideration to the effect of uncertainty and knowledge (Demsetz 1991). However, uncertainty is arguably a core issue in innovation, in addition to being at least as important as asset specificity in general (Geykens, Steenkamp and Kumar 2006). Recent work has in fact increasingly acknowledged the role of uncertainty, identifying trade offs between the incentive properties of various contractual schemes and their capacity of adaptation to uncertain 
conditions. The notion employed has typically been that of optimally incomplete contracts, and the typical empirically testable propositions have been that the higher the uncertainty, the lower the optimal degree of completeness, articulation and formalization of contracts (Croker and Reynolds 1993; Bernheim and Whinston 1998, Battigalli and Maggi 2001; Bajari and Tadelis 2001) and that the higher the competitiveness of the game (the less aligned the objectives are, the more conflicting interests are) the higher the optimal level of formalization and of specification of contingent claim clauses (Klein 2000). These propositions go along with the theorem that, if uncertainty and conflict of interests are both simultaneously present at high levels, contracts fail altogether as a mode of regulation, because of their 'incompleteness', and need to be complemented by extra-contractual governance mechanisms, either based on authority or power (Williamson 1975, 1979; Grossman and Hart 1986; Hart 1988; Tadelis 2002), or based on socially accepted norms (Macaulay 1993; Al Najjar 1995; Ouchi 1979; Ring and Van de Ven 1992)

If we were to accept those conclusions, we should model the problem of optimal contractual configuration as an optimal degree of formalization and completeness, resulting from the opposite pulls of the two predictors. We should expect very low formalization/completeness if only uncertainty is high; very high formalization/completeness if only conflict is high; an intermediate level of formalization and completeness if both the antecedents are high; and possibly only informal handshaking or very simple complete contracts where neither uncertainty nor conflict are significantly present.

There are problems with this view, though; and, we argue, there are better solutions than just trading off losses in enforceability with losses in flexibility. 
Empirically, there are anomalies with respect to that framework. In reality very uncertain, complex, innovation oriented collaborations are often conducted across firms and are regulated by very simple and short contracts, even when the partners cannot be assumed to share the same culture and norms, nor to share objectives and preferences, as they have little experience of previous collaboration with each other or they engage in very different fields of activity. As a few interesting empirical researches conducted by economists have shown, contract clauses in innovative ventures tend to focus on few core matters, rather than entering into possibly relevant 'myriads of details' about future activities (Lerner and Merges 1998).

Theoretically, it can be argued that both the optimally incomplete contract solution and the relational contract solution have limits in their capacity to dealing with strong uncertainty and radical innovation.

As to the optimally incomplete contracts solution, it should be noticed that, for any analysis of that kind be feasible, the level of uncertainty that is tractable (and indeed the only type of uncertainty that is treated in the economic literature on the topic) is limited to situations in which a trade-off between the costs and expected benefits of 'completeness' can be calculated (Grandori 1984, 2005b). These conditions are recurrent and relevant in economic activities, for example construction projects, procurement relations, and pricing behavior, but they are not the only ones. The conditions of uncertainty that characterize innovation, however, are different, and have in fact been characterized as conditions of 'Knightian', 'structural', 'epistemic' uncertainty, rather than just of complexity or variability (Schakle 1972; Langlois 1986; Grandori 1984, 2005b). The core issue is to discover interesting problems, actions and action-outcomes, causeeffect relations and not just to foresee which states of the world and contingencies will materialize in the future. The present article paper expands available assessments of the 
'cognitive' properties of contracts (as opposed to only their incentive properties), by considering also and especially how they allow actors to discover relevant actions, rather than just to 'adapt' to circumstances. ${ }^{\mathrm{i}}$

As to the relational contract solution, it has been highlighted that the notion encompasses different meanings, but that, in all of them, its effectiveness is also bound to conditions of limited uncertainty (Grandori 2006). In a first meaning, it is argued that if the structure of the game is sufficiently cooperative, parties see net advantages in cooperating, agreements can be 'selfenforcing' and there is no need for formal, court-enforceable contractual protection (Klein 2000; Baker, Gibbons and Murphy 2002). Others propose that when there is the possibility of a conflict of interests (or even the potential of opportunism), and when actions and contingencies are not specifiable, then the solution consists of the assignment of 'residual' (that is, contractually unspecifiable) decision and reward rights to one party, so that the uncertainty about what should be decided is resolved by specifying who will decide rather than what will be done.

Stated differently, the solution is extra-contractual, and lies in the establishment of a hierarchical order, based on authority or on the power of one party (Williamson, 1975; Grossman and Hart 1986). If however no single party can develop reliable proxies for monitoring behaviors (as it is typical in very uncertain settings), norm based, 'socially enforced' compliance is envisaged as a solution (Ouchi 1979; Williamson and Ouchi 1981; Macaulay 1963). Both 'selfenforceable' informal contracts and 'socially-enforceable' informal contracts, though, entail information requirements that are not particularly representative of highly innovative ventures. In fact, in calculative 'incentive-based' cooperation, it should be known what relevant actions and payoffs are; and in non-calculative 'norm-based' cooperation it should be known what behaviors are appropriate and it should be observable whether they have been implemented. So, 
again, this is no satisfactory solution to the problem of regulating very innovative and uncertain collaborations.

There is however a third notion of relational contract that is less used but more useful as a component of contracts under uncertainty. In political constitutional economics and law, relational contracts have been conceived as systems of decision rules as opposed to action specifications and normative models of behaviors, and as 'constitutions' of societies rather than as regulations of exchanges (Vanberg 1994; Goldberg 1976; Macneil 1978). In other terms, relational contracts in this meaning could be characterized as 'procedural' as opposed to 'substantive' (Simon 1976), rather than as informal versus formal (Grandori 2006). Precisely thanks to this feature, procedural constitutional contracts can be an important ingredient of formal contracts capable of being both adaptive and protective of differentiated interests under strong uncertainty. However, we argue that this is only a partial response, only one component of viable agreements for innovation, as some substantive pacts are also needed, albeit not about actions, but about actors. ${ }^{\text {ii }}$

\section{Associational Contracts for Innovation}

The puzzle of contracting under uncertainty can be solved by disentangling the notion of contract from that of market-like coordination, and the notion of organization from that of extracontractual governance. In principle, any coordination mechanism can be specified in a contract: from prices to the nomination of authorities; from voting schemes to consultation and negotiation procedures; from plans to programs to be followed in production and exchange (Grandori 1999). Contracts can be analyzed according to the extent they embody those qualitatively different 
mechanisms, rather than according to some linearly varying dimensions (such as completeness, articulation or formalization). In this perspective, the rightly posed question for understanding and designing contracts for innovation would be which collection of clauses would compose a formal and enforceable, but flexible and open contract, capable of locking in resources without unduly constraining behaviors? Which combination among coordination mechanisms needs to be specified in the agreement?

A first important requirement for such a contract seems to be that it should not define what contracts are typically supposed to define, namely, which actions are to be taken under what contingencies. If so, then the contract would in fact become rigid (in the lack of omniscience). Does this amount simply to saying that contracts should be, to some extent, incomplete, taking into account the cost of foresight, writing and enforcement (Loasby 1976)? We think that this is not the entire story and that we should look at what is in the contract, rather than only to what is left out as the former may explain the latter.

Organization theory indicates some control modes that are more compatible with uncertainty than the specification of actions and the control by monitoring deviations from promised actions. A first alternative is control by results, or outputs, rather than control on actions or inputs (Locke 1996). A contract on outputs to be reached or delivered is more flexible as it does not prescribe how to reach them (leaves flexibility at the level of actions). However, it is also known that control 'by objectives' and 'goal setting' is dangerous in very innovative activities, such as most research activities, as it generate a 'tunnel effect' and actually requires that what is to be discovered is already known (Locke 1996). Hence, the modes of control that may be expected to be effective where both inputs and outputs are unspecifiable should be abstract and content-free, general missions rather than precise goals, principles rather than 
routines, decision procedures rather than actions and results, rights on residual results rather than on substantively specified outputs. In fact, empirical research on what is there in the contracts that regulate innovative collaborations consistently shows that they focus on a few core matters, which are different in kind with respect to actions, contingencies and specified outputs. Contracts for innovation are focused on the terms of association between actors and the specification of their rights: who the participants are, which resources they will contribute, what the limits and liabilities of these commitments are, under what conditions and how the participants can withdraw those resources, who owns what, how the 'surplus' and output resulting from collaboration (independently of its specific content) will be distributed (Suchman 1994; Kaplan and Strömberg 2003; Grandori and Furlotti 2006).

These elements define what can be called an 'associational contract' (Grandori 1999, 2005a), as they establish an association or society rather than regulate an exchange $\mathrm{e}^{\mathrm{iii}}$. The nature of resources and the degree of association can vary. It can be an association of financial capital (a joint-stock or incorporation contract), or of human capital (a partnership, or an association of people), with or without common ownership of technical assets, and with varying levels of other property right sharing (Daems 1983; Grandori 1997; Brouwer 2005). As these authors all highlight, the presence and extent of property right sharing further qualifies and distinguishes the intensity and properties of those associational contracts. Joint ventures and consortia are stricter associational contracts, and are more suitable to regulate collaborations for innovation, than, say, a commercial associational contract regulating the common use of a brand. Hence our conjecture is that the key feature that distinguishes associational contracts for innovations from other associational contracts is rooted in the distinction between resources and the services that they might deliver (Penrose 1959). Such contracts do not and should not stipulate specific common 
actions, but do and should stipulate the association of resources from which actions, unknown at the moment of contract, will derive. Contracts for innovation can therefore be further qualified as resource-based (as opposed to action-based) associational contracts (Grandori and Furlotti 2006).

In line with the theory developed so far, in the empirical part we inquiry into the specification of actions and expected results, into the rights and obligations on resources and outputs, and into the conditions for exiting the relationship.

Even in the case of tight, resource-based, proprietary associations, though, the agreement of associating resources needs to be complemented by a 'constitutional' agreement on how decisions on their use will be taken, whatever these uses might be, and precisely because they are not known ex-ante. Not all constitutions are alike though, and highly innovative, discovery oriented systems are compatible and complementary only with some types of rules and not with others.

First, not all kinds of rules perform nicely under uncertainty. At the opposite, organizational research has generally highlighted the 'rigidity' of this component of bureaucracy. A solution to this problem, that is, a way to achieve 'flexible formalization' capable of coordinating action under uncertainty, is to use only high order, content free, framing rules of the game, specifying how to make decisions (Grandori 1999, 2006; Grandori et al. 1999), as contrasted with substantive rules, as 'programs' or 'routines', specifying which actions to perform under what circumstances (Simon 1960, 1976; Cohen et al 1996).

Second, a constitutional contract may specify a variety of coordination mechanisms to be used in adjusting partners wills. They include at least incentive-based coordination, hierarchical 
coordination (more or less delegated), joint decision-making (team-like, negotiated or representation-based), and rules (varying in their degree of generality) (Miller 1992; Fiske 1992; Grandori 1999).

The effectiveness of such mechanisms is known to be extremely sensitive to the levels of uncertainty, though. In particular, it is known that the very high level of uncertainty connected to innovation are likely to generate both 'market failures' and 'hierarchical failures' (Grandori forthcoming); as well as it leads to failure also action-specific, detailed rules (programs and routines, task and job descriptions, contingent planning). Two among the basic coordination mechanisms emerge as more robust under uncertainty. They are high level, general, mission-like, constitutional rules of the game, as distinguished from detailed, action specific task descriptions, and joint decision-making procedures, especially representative multi-party decision making, if the relevant knowledge for selecting actions is distributed. (Miller 1992; Grandori 1999).

In keeping with this framework, in the empirical part we shall trace the intensity of procedural (versus substantive) clauses in contracts and the degree of generality (versus detail) of the rules and procedures embedded into contracts..

On the basis of the above premises, we set out the hypothesis is that the optimal contractual configuration for innovation - that is, contracts capable of governing cooperation under radical uncertainty (activities and transactions to be discovered) and high conflict potential (future judgments on best actions may always differ) - is formal (enforceable) but flexible (adaptive); and that this configuration can be specified as follows.

H1: The formal, enforceable core of these contracts is composed by a 'strictly associational' part - specifying the fundamental obligations and rights as to resource 
commitment and outcomes appropriation (rather than tasks) - and of a 'strictly constitutional' part specifying the fundamental decision rules and procedures (rather than substantive and detailed action plans).

A second hypothesis is that high intensity in property rights deliberate allocation and sharing should not imply a high intensity in hierarchical coordination, based on authority or on unilateral power, as most often assumed in organizational economics works. As organization and coordination theory ever since showed, where pooled resources (in particular knowledge resources) are distributed across different partners and problem solving is complex and innovative, coordination by hierarchy and plans is not effective, but team-like and horizontal coordination should prevail. Hence:

$\mathrm{H} 2$ : In contracts for innovation the property right sharing associational agreement is complemented by a 'democratic' (rather than hierarchical) constitutional agreement (Grandori and Furlotti 2006; Lammers 1993).

In sum, we expect effective contracts for innovation to be associational (rather than transactional), resource-based (rather than action-based), constitutional (rather than operational), democratic (rather than hierarchical). More operationally, in analyzing the clauses and provisions contained in contracts for innovation, we expect to find that they approximate the following profile $\mathrm{iv}^{\mathrm{iv}}$

low incidence of both market-like and bureaucratic coordination; high incidence and complete specification of proprietary associational rights and obligations; low degree of articulation and a small number of contingent clauses; 
high degree of procedural completeness, realized thanks to a contractual specification of decision making procedures (rather than decision content);

high incidence of strictly constitutional, procedural rules of decision making; decision procedures approximating a democratic order (joint direct or representative decision making, negotiation), rather than a hierarchical order (decision making rights assigned to one party).

It can be finally argued that those mechanisms, not only fit conditions of high uncertainty and high conflict potential but are also complementary to each other. In particular, the foundation of an association between parties would be incomplete without the specification of how to make the ad hoc decisions on actions and vice versa; hence the associational and constitutional components of those contracts are strictly complementary. Additionally, the proper working of these mechanisms, that provide flexibility, is complementary with a low ex-ante description of tasks and contingencies, and of the substantive terms of exchange (good and service transfers and prices); that is, with limited intensity of the bureaucratic and market components of contracts. Finally, associational and constitutional governance is complementary with multiparty, rather than unilateral, allocation of decision rights, in order to provide adequate incentives to invest resources for all parties, and to mobilize all relevant competencies for taking high quality decisions in new problems.

\section{Content-analyzing Contracts: Evidence from a Comparative Case Study}

\section{The four alliances}

The particular empirical setting we have selected for an explorative assessment of whether actual contracts conform to the predicted model is that of technology collaborations in pharmaceutical 
biotechnology. Describing the characteristic of this industry is beyond the scope of this work. The interested reader is referred to the works of Gambardella (1995) and Henderson, Orsenigo and Pisano (1999) to understand why this setting almost archetypically exhibits those conditions - high uncertainty, distributed knowledge, conflict of interests - which should be conducive to an intensive use of resource-based associational contracting.

The research design is a comparative case study, where cases are selected with purposes of analytic rather than statistical generalization (Yin 1984). Yet the alliances have been picked from a random sample of 79, drawn from a population of about 1700 collaborations between business companies for which a business service provider had gathered the alliance agreement as well as complementary information. ${ }^{\mathrm{v}}$ The alliances in the random sample involve at least one US partner, and US law applies to almost all the contracts. All the alliances considered are researchbased, innovative projects. They have been selected so as to differ in two important respects. First, alliances B and C were entered at earlier stages of the discovery process and involved relations between biotechnology research firms only. The other two were entered in later, more applied stages and involved vertical relations between biotech firms and downstream pharmaceutical firms. Alliances B and C can then be characterized as involving more uncertainty and interdependence, than A and D. Second, alliances B and A are characterized by very balanced resource contributions, while $\mathrm{D}$ and $\mathrm{C}$ were more asymmetric. This introduce in the sample an important control variable, as, both according to property right theory and negotiation theory, the distribution of decision and property rights to may be sensitive to the amount and criticality of contributions (Raiffa 1982; Hart and Moore 1990). All alliances are to be considered 'successful', at least in the sense that there is evidence of progress of the collaboration through successive stages of the drug discovery. One final criterion that guided the 
choice of these four alliances has been the requirement that the agreements had few, if any, excisions of text for confidentiality reasons. Content analysis of the contractual documents provides the bulk of the evidence that has been used for this study. Additional information, whether collected directly or supplied by Recombinant Capital, has been gathered from press releases, annual reports and company filings to the US Securities and Exchange Commission. Content analysis of the four agreements has been accomplished by one of the authors, with the aid of qualitative research software N6.

Alliance $A$ was established in 2005 between Nuvelo Inc. and the pharmaceutical division of Kirin Brewery Company of Japan, and was designed to develop and commercialize products for the treatment of inflammatory diseases, based on a particular protein that had been identified in a prior collaboration. Under the terms of the agreement Nuvelo would lead worldwide development, manufacturing and commercialization activities. All expenses and operating profits would be shared in a 60 (Nuvelo) /40 (Kirin) ratio. Kirin was not expected to carry out any particular task, except if Nuvelo so requested and Kirin accepted. The contract establishes that the alliance will continue as long as either party develops or commercializes any product.

Alliance B was established in 1998 between Biosearch Italia S.p.A. and Versicor, Inc. to exploit the complementary know how of the two firms. In practice, Biosearch contributed natural product antibiotic leads while Versicor contributed skills and efforts to optimize those leads. All primary care antibiotics derived from the collaboration would be partnered to large pharmaceutical companies with the revenues shared 50 - 50 between the two companies. The contract envisaged a development program term of five yeas, extendable by mutual agreement. The collaboration between Biosearch Italia S.p.A. and Vicuron Inc. went on for about five years, until the two companies merged. 
Alliance C, a 2004 collaboration Between Sunesis Pharmaceuticals, Inc. and Biogen Idec was the second between the two companies and it was designed to discover and develop small molecule cancer therapeutics targeting kinases, a family of cell signaling enzymes. The companies would apply Sunesis' proprietary drug discovery technology. Under the terms of the agreement, Sunesis would receive upfront a \$7 million technology access fee and \$14 million equity investment, research funding, milestone payments, and royalty payments based on product sales. Biogen Idec acquired exclusive licenses to develop and commercialize the compounds resulting from the collaboration. Sunesis retained an option to participate in the co-development and co-promotion of several products. A team of Biogen Idec and Sunesis scientists will work together. The contract establishes a period of four years for research activities (extendable for up to an additional two years), while ongoing activities of the alliance would last until there are royalty payment obligations.

Alliance D, established in 1999 between Alexion Pharmaceutical Inc. and a subsidiary of Procter \& Gamble, was designed to develop and commercialize Alexion's lead drug candidate pexelizumab, and to assess it in a few acute cardiovascular indications. P\&G would receive worldwide development and marketing rights. In return, Alexion would receive up to $\$ 95$ millions in total payments (of which, 10 millions upfront), including up to $\$ 39$ million in precommercialization milestone payments. In addition, Alexion retained the right for commercial manufacturing and co-promotion in the U.S.

As already mentioned, the grid for the content analysis of contracts investigates the associational part of the contract by asking about the relative specification of actions and expected results, rights and obligations on resources and outputs, and rights of exit from the relationship; and it 
enquiries into the constitutional part of the contract through the observation of rights and procedures for ex-post decision making, and dispute resolution.

\section{The Associational Substantive Contract}

\section{Actions and expected results}

In general the contracts are quite concise, considered the time span and activity scope of the ventures. They range from 7,500 words in the case of alliance B to 30-40 thousands in the other cases). Information on the articulation of tasks may also come from the proportion of contract that is dedicated to the specification of research and commercialization plans. In both alliances A and $\mathrm{D}$ the research plan occupies about $10 \%$ of the contract, while in alliance $\mathrm{B}$ the ratio plunges to less than $2 \%$. Therefore, in all the alliances the specification of the actions to be carried out by the parties takes up only a minor portion of the respective contracts.

The research plans in the four agreements differ also by their content. Alliance B's plan, the shortest of all (108 words), simply names ten steps that indicate the fundamental tasks of the parties, without any articulation. On the contrary, alliance C's initial research plan is fairly detailed. It identifies 59 distinct activities to be performed, it determines the allocation of resources and it provides a Gantt chart of activities. The plan is further detailed through the specification of several criteria that will guide the assessment of whether to bring a certain molecule to the next phase of development or not. Alliance D's initial R\&D plan is also fairly long (8 pages). Yet it is entirely procedural. Essentially it recaps the projects in progress as of the effective date of the agreement and assigns the basic action duties with respect to sections of the program. 
Downstream activities (commercialization and manufacturing) are scarcely planned in all the four alliances, when they are not lacking altogether. They describe actions sketchily and establish who has the right/responsibility to perform manufacturing and commercialization and under what conditions. Even less than observed in research and commercialization plans, the contract does not enter into the details of how to perform regulatory filings, patent applications and the defense against patent infringements. The essence of these stipulations revolves around the specification of who has the responsibility (or the right) to carry out the assignment, under what circumstances the responsibility may shift to the other party, and who shall bear the costs and enjoy the benefits associated with it.

As to expected results, the goals to be reached are specified in very general terms. In this respect the four alliances show very little variance. Alliance $\mathrm{C}$ may be taken as an example for all. The opening section of the contract states what the output of the collaboration is expected to be:

"C. Sunesis and Biogen Idec wish to collaborate to discover and develop small molecules that modulate certain Targets, especially Kinase Targets, with the goal of delivering compounds with desired activity and selectivity."

Then for further information on the expected output, we are referred to the Research Plan. However, after restating the mission of identifying novel inhibitors of protein kinases, the plan simply adds that this serves the purpose of optimizing them to identify Development Candidate compounds. When moving to the part that should specify what optimized compounds look like, the contract switches to language that is very rich in terms of the description of process but extremely poor of substantive specifications. 


\section{Rights and Obligations on Resources and Outputs}

As opposed to obligations to perform particular activities, or to deliver specific outputs, the obligations and rights about resources and outputs, are definitely less hazy.

Who should contribute what, and who owns what, is ubiquitously and precisely defined. In addition, restrictions to any change on that ground are also common. In some cases the restrictions to the transfer of rights underscore the importance of the counterpart's identity in quite strong terms. In alliance $\mathrm{C}$, the contract establishes that upon a change of control some rights of the acquired party shall terminate. In alliance $D$, if the $R \& D$ firm experiences a change in control, $P \& G$ can sell its interest in the alliance to the R\&D firm itself or to third parties.

Project costs are generally specified accurately both as to their amount and to their incidence. In alliance A the financial budgets of the activities are a cornerstone of planning (the word 'budget' is mentioned 248 times). Budget overruns are tightly capped. In alliances C and D the financing party achieves budgetary control through the specification of the number of personnel full-time equivalents (FTE's) it will fund and of the FTE rate to be used in the calculation. On the contrary, alliance B stands out (no budgets), as its basic arrangement (each carries out its own activities and bears their costs) requires no foresight of monetary input factors in the contract.

A second input to the collaborations is the intellectual assets that the companies bring to them. Biotechnology alliance contracts never forget being specific about the incidence of intellectual property rights (IPRs) brought into the collaboration (background rights) or generated by it (foreground rights). In all the alliances the background rights licensed by the R\&D firm are explicitly listed in an appendix to the contract. Further specifications concern the extent to which IPRs can be used in the collaboration. 
Turning to outputs, a high degree of specification can be observed also with regards to the benefits of the collaboration. The main valuable outputs specified in technological collaboration contracts are flows of monetary revenues and newly developed intellectual property.

In the contract in our sample the incidence of monetary revenues is always crystal clear and in all cases it entails some sharing of sorts, through the payment of royalties [Alliances $\mathrm{C}$ and D] or the equal sharing of profits [Alliance A] or revenues [Alliance B]. As to the arrangements concerning newly developed intellectual property, it is useful to distinguish residual from non-residual rights. Usually alliances regulate separately these two classes of rights, since they assign ownership (residual rights) distinctly from the rights to use the intellectual property for the specific purposes of the collaboration. Different arrangements on residual rights can be observed in our sample. Contracts in alliances A and B are rather communitarian, as already seen with monetary rewards: inventions are to be owned jointly, regardless of invention's source. On the contrary, in contracts in alliances C and D specific incidence is the rule: each owns the inventions generated by its own employees.

Regardless of who obtains the ownership of newly developed intellectual property, it appears that the parties may effectively assign to either of them, or to both, the right to put to use that property in specific applications. Such assignment is accomplished by the specification of several items. Among them the most important are: what set of background and foreground rights is licensed; whether the license is exclusive or not (i.e., whether it excludes the licensor from the possibility to exercise the licensed rights); the kind of activities for which the license is granted (e.g., research, manufacturing, sales, etc.); a field of use, usually defined in terms of the particular molecules licensed and the therapeutic indications they may be used for; the 
geographic territory and the period for which the license holds; whether the rights can be sublicensed and at what conditions; the royalties to be paid for the right of use; royalty accounting provisions detailing the criteria to calculate the amounts due ${ }^{\text {vi. }}$, and, finally, whether

either party (generally the licensor) is granted any particular option, like, for instance, that of copromoting or co-manufacturing.

\section{Exit rights}

Although certain language underscores the importance of the relationship, contracts also acknowledge that relations alone cannot rescue an alliance that has completely lost its economic rationale, and they grant rights to terminate the relation ahead of time. The contracts in our sample differ considerably as to the latitude of the rights of not-for-cause termination granted to the parties. ${ }^{\text {vii }}$ Alliance $\mathrm{D}$, that requires either mutual consent or the determination by an independent third party of the "collapse" of the scientific rationale is the most restrictive. On the opposite end of the spectrum, alliance A grants to both parties the right to terminate the alliance in its entirety without cause.

Alliance $\mathrm{C}$ also grants unilateral termination rights for convenience quite generously, but only to the financing party. The only restriction is that such party serves a notice period and, in the case that termination occurs very early in the life of the alliance, that it pays a cancellation amount.

In alliance B unilateral termination is available to both parties, with limits. The party contributing the core intellectual property - Biosearch - is not allowed to withdraw from the alliance until the completion of pre-clinical studies. For later stages, individual withdrawal is allowed, but somewhat discouraged through a lower share of future revenues that the non- 
investing party shall be entitled to receive. Unlike Biosearch, Versicor can unilaterally leave at an earlier stage, but that would be quite contrary to its incentives, since all rights to collaboration compounds would revert to Biosearch and Versicor would receive neither monetary compensations for the work accomplished, nor any share of future revenues.

The reversion of IPR to the non-terminating party is common to all the other alliances. This covenant underscores once more the centrality of resources. In a sense, once resources are contributed to the 'association' they are granted forever. In sum, relations are not sacred: extreme adaptation through early termination is possible in all the alliances of our sample. However, the right to disengage from the relation only relates to the actors, while resources remain to a large extent 'locked in'.

\section{The Constitutional, Procedural Contract}

\section{Decision rights and procedures}

Contracts typically include reference to some institutionalized fair play rules or 'codes of conduct' that should be followed in delivering whatever will be delivered. These are 'facio ut facias' rather than a 'do ut des' agreements, and they are about general principles to be followed, rather than substantively specified behaviors.

A common principle is 'due diligence', frequently defined as "commercially reasonable effort" [Alliance D]. Sometimes it is defined by reference to "applicable standards" for industry practices [Alliance C]. Other alliances make reference to particular regulations, like FDA-issued cGMP (Current Good Manufacturing Practices) [Alliance A].

Another common principle is 'full cooperation'. Most contracts explicitly mention a commitment to 'full' rather than perfunctory collaboration during the life of the agreement. All 
the contracts in our sample require that the parties do not engage in external activities that can be detrimental to the relation.

Counter-intuitively, where principled cooperation is the least invoked is in the alliance were the contract is minimally articulated [Alliance B], confirming the suspect that there must be something else and something more than contract articulation or extra-contractual relational cooperation in these agreements.

More operational, more substantive, codes of behavior, commonly inserted in contracts, are non-competition and exclusivity clauses. However, paradoxically, these clause are typically not enforceable under the US law: a confirmation of the suspect that contracts are not there just for being enforced by courts.

Other procedural clauses are not taken from the 'generally accepted' norms of good behavior, but are relation- and partner- specific. These clauses define a governance 'regime' by specifying which parts are entitled to adjust plans and according to which decision procedures. Plans, in turn, are openly admitted not to be strictly binding even when they are present. They are to be intended as hypotheses to be revised, the more so the closer to the operational level the matters dealt with are. As a result contracts concede that plans will undergo modifications or will be agreed upon after the start of the alliance. In all the focal alliances joint decision-making stands out prominently as a mechanism for adaptation.

In all the agreements in our sample a Joint Steering Committee (JSC) plays some role in the process of revision and of further specification of existing plans, and of approval of entirely new plans. Alliance B offers the most egalitarian arrangement: the JSC is composed of an equal number of members from each party, decides by unanimous vote, alternates the Chairmanship between the parties on a yearly basis (with the Chairman holding no tie-breaking vote) and is 
vested with the full and undivided powers to make these changes. Except for minor differences, the functioning of the JSC in alliances C and D is similar to the one just described. Alliance $\mathrm{A}$ is partially an exception as it gives a final say to the R\&D firm in case of disagreement over research matters. However, joint decision-making is again resorted to in the case of downstream activities, where no party unequivocally holds a superior know-how and the decisions involved are high in conflict potential.

With the exception of alliance B, which is unwaveringly egalitarian, also in the other alliances the powers of the JSC are complemented by assignments of unilateral decision rights in specific areas. However, when this is the case, the assignment of unilateral decision rights tends to be mitigated by the requirement that the exercise of authority follows a particular procedure. ${ }^{\text {viii }}$ Moreover, to some extent the assignment unilateral decision rights seems to follow a logic of efficiency as it usually concerns decision areas where the assignee holds superior knowledge. ${ }^{\text {ix }}$ The assignment of unilateral decision rights to one party exposes the other to risk. Contracts generally limit such exposure through various safeguards, above and beyond the prescription of a certain procedure. In alliance $\mathrm{D}$, as we have just seen, these are in the form of verifiable criteria, set ex-ante 'under a veil of ignorance', that must be met in order to exercise the decision right. In alliances $\mathrm{A}$ and $\mathrm{C}$ the safeguard is provided by the requirement of consistency with the contract. Although less frequent than those concerning tasks and actions, adjustments in the basic terms of the association are also possible and suitable procedures are provided for.

Some mechanisms for the adjustments concerning resources have already been mentioned. One of them is the stipulation in alliance A, that the amount of budget overruns which the client may be asked to underwrite, is limited to a pre-specified percentage of the original budget. Another is joint decision making, which was prescribed in the same alliance for 
the determination of commercialization budgets. As seen before, this solution contrasts with the right granted to Nuvelo to make a final determination on development plans. Thus in alliance A we observe the use of separate decision-making processes for issues impinging upon resources and issues that just relate to actions. ${ }^{\mathrm{x}}$

While resources are almost untouchable, except than by mutual consent, marginal adaptations are sometimes carried out in a non-calculative, formulaic way (e.g., R\&D funding subject to periodical adjustment for changes in the Consumer Price Index [Alliances C and D]). In other cases, they are dealt with through the explicit foresight of contingencies. One issue for which this solution is commonly adopted is the possibility that in the course of the alliance the parties discover that the products under development cannot be sold unless a license on third party patents is obtained. Alliances A, C and D deal with this possibility by spelling out unambiguously who, under what circumstances and in what proportion should contribute those additional resources.

As an adaptation mechanism, contingency clauses find application not only with resources but also with action rights and with rights on outcomes. One such case is the provision, in alliance $\mathrm{D}$, that royalty payment be reduced if sales of non-infringing generic equivalent products exceed a certain market share. Other cases are the provisions that Alexion's right to comanufacture [Alliance D] and Biosearch's right to manufacture [Alliance B] are subject to proven capacity to meet a number of criteria.

All in all, the foresight of contingencies is used rather sparingly, to provide flexibility with regards to issues that would be too contentious to be solved through negotiation or through unilateral decisions, yet too important to forego the value entailed by adaptation. ${ }^{\mathrm{xi}}$ Another 
condition for the use of contingency planning seems to be the possibility to identify the triggering event in a rather unambiguous way.

\section{Dispute Resolution}

The importance of the association is underscored also by the provision, common to all the alliances, of mechanisms to keep it afloat when disputes surface. The typical set of mechanisms, which is found also in alliances outside the focal sample, envisages the escalation of disputes to senior executives for settlement in an amicable way through negotiation. Failing that, the procedure provides for arbitration by a panel of legal experts [Alliance B]. Normally, arbitration is final, meaning that the dispute cannot be brought also to court. Some of the alliances in our sample provide also for even leaner dispute resolution mechanisms, when the decisions are to be based on practices of the industry or scientific judgment, rather than the law.

Thus a wide array of soft dispute-resolution mechanisms is available. Nonetheless, there seem to be cases when disputes undermine the relation beyond repair to the point that the parties turn to uncompromising confrontation. This is the case in alliance $\mathrm{C}$ (for matters relating to intellectual property, and for breaches of warranties and representations) and alliance D (default of payments, breaches of confidentiality, indemnification and insurance). Tellingly, most of these triggers of litigation are closely related to resources.

\section{Conclusions}

This study has offered some theoretically derived propositions on the nature of inter-firm contracts under strong uncertainty. The propositions predict well the general pattern observed, in this comparative case study. However, the case studies suggest some refinements. This 
concluding section summarizes the findings that are analytically generalizable against the advanced propositions, indicates which conceptual refinements are suggested, and indicates how this line of research can be further developed.

The more robust regularity regards the degree of specification of the core associational and constitutional contract: all contracts avoid entering into details about tasks and specific outputs, while completely specifying property rights on resources. These property rights are shared, as expected. In addition, in all four alliances, resource-based associational contracting is complemented by procedural contracting, specifying how decisions will be made. Pricing and detailed ruling figure less prominently in the documents analyzed.

The type of procedures for adaptation employed (the democratic versus hierarchical nature of the constitution), instead, are more varied and less straightforwardly linked to the main predictor considered in the hypothesized propositions, namely the level of uncertainty. The configuration of results across the four case studies support our 'control' conjecture, used for constructing the sample, that the relative importance of the contributed resources could have been a fundamental intervening variable for understanding the particular regime adopted. In fact, the alliance that more closely approximates a democratic order is alliance B, which is also the only alliance that meets both the conditions of high uncertainty, and high symmetry of contributions.

A development of the study presented here is to statistically test the conjectures advanced here on large samples of contracts and interfirm alliances. This test is being carried out by the authors on questionnaire data on a sample of 500 inter-firm project-based alliances (the KGP project database). ${ }^{\text {xii }}$ The general pattern emerging in that database, relevant for the theme considered here, is broadly consistent with the conclusions of our comparative case study, in that " property 
rights $(\ldots)$ are widely shared, different rights are allocated to different partners, and their distribution comes close to fair division rules such as the proportionality to investments (of various types of resources) rather than to concentration and co-location of different types of rights in the hand of 'the' critical investor.' (Grandori and Furlotti 2008).

Quantitative analyses have been also conducted on the entire sample of the 79 contracts, from which the four case studies presented here were selected for in depth examination (Furlotti 2007, 2008). The general pattern in that larger sample of contracts is that a certain degree of contracting on resources can be recognized in most agreements, while the extent to which this associational clauses are combined with traditional clauses centering on output and incentives, or on actions and control rights, varies. Joint decision making is the basis of action in most agreements. However, even in the larger sample it was possible to detect heterogeneity in the constitutional part of contracts, with more egalitarian regimes adopted when the resource contributions of the parties are approximately balanced.

In addition, the detailed examination of contracts conducted in the present case study shows that the governance mechanisms embodied into contracts exhibit varying degrees of centralization within each single alliance. This finding suggests that the rights and obligations on procedural matters are sensitive to the fine-grained configuration of activities rather than to the overall characterization of an alliance. The organizational perspective that we are using to complement the economics of contracts would suggest that the varying complexity of different tasks, and the different concentration of knowledge on each of them, within any single alliance, can explain why and where unilateral, trilateral or joint decision making procedures are used in task selection. Hence, future research in this line should benefit from breaking down the level of analysis, from the characterization in terms of uncertainty, relative incidence of contributions or 
other variables of an entire 'alliance', to that of the specific transactions and cooperations that compose it.

\section{References}

Al-Najjar N.I. 1995. "Incomplete Contracts and the Governance of Complex Contractual Relationships.” American Economic Review Papers and Proceedings 85/2:432-36

Bajari, P., S. Tadelis. 2001. "Incentives versus Transaction Costs: A Theory of Procurement Contracts." RAND Journal of Economics 32(3): 387-407.

Baker, G., R. Gibbons, K.J. Murphy. 2002. Relational Contracts and the Theory of the Firm. Quarterly Journal of Economics 117(1): 39-84.

Battigalli P., G. Maggi. 2000. "Imperfect Contracting.” Working paper, European University Institute and Princeton University.

Bernheim, B.D., M.D. Whinston. 1998. "Incomplete Contracts and Strategic Ambiguity." American Economic Review 88(4) 902.

Brouwer, M. 2005. "Managing Uncertainty through Profit Sharing Contracts from Medieval Italy to Silicon Valley.” Journal of Management and Governance 9(3-4): 237-255.

Crocker, K.J., K.J. Reynolds. 1993. “The Efficiency of Incomplete Contracts: An Empirical Analysis of Air Force Engine Procurement.” Rand Journal of Economics 24(1): 126-146.

Daems H. 1983. “The Determinant of Hierarchical Organization of Industry”. In Power, Efficiency and Institutions, ed. A. Francis, J. Turk and P. Willman. London: Heinemann. 
Demsetz H. 1991 “The Theory of the Firm Revisited”. In The Nature of the Firm: Origins, Evolution and Development, ed. O.Williamson and S.Winter, 159-178. Oxford: Oxford University Press.

Fiske, A.P. 1992. "The Four Elementary Forms of Sociality: Framework for a Unified Theory of Social Relations.” Psychological Review, 99: 689-723.

Furlotti, M. 2007. "Planning for Risk or Planning for Performance? Managing Resource Requirements and Coordination Concerns in Technology Alliance Agreements”. Milan, Bocconi University, Crora Working Paper n. 20.

Furlotti, M. 2008. “Contracts as an Organizational Phenomenon: An Empirical Taxonomy of Technology Alliance Agreements”. Bocconi University, Crora Working Paper n. 21.

Gambardella, A. 1995. Science and Innovation. The US Pharmaceutical Industry During the 1980s. Cambridge: Cambridge University Press.

Geykens, I., J-B.E.M. Steenkamp and N. Kumar. 2006 "Make, Buy, or Ally: a Transaction Cost Theory Meta-analysis." Academy of Management Review 49(3): 519-543.

Goldberg, V.P. 1976. "Regulation and Administered Contracts." The Bell Journal of Economics 7(2): 426-448.

Grandori A. 1984. “A Prescriptive Contingency View of Organizational Decision Making.” Administrative Science Quarterly, 29: 192-208.

Grandori, A. 1999. Organizzazione e Comportamento Economico. Il Mulino, Bologna. Published in English as Organization and Economic Behavior. London Routledge, 2001

Grandori, A. 2005a. Firm-Like Contracts: From Task Contingencies to Resource Commitments. Milano: Bocconi University. Crora Working Paper n. 10. 
Grandori A 2005b. From Bounded to Epistemic Rationality: Economic Decision Making as Rational Discovery. Milano: Bocconi , University. Crora Working Paper n. 11.

Grandori, A. 2006. “Innovation, Uncertainty and Relational Governance.” Industry \& Innovation 13(2): 127-133.

Grandori A. forth. "Poliarchic Governance and the Growth of Knowledge." In Knowledge Governance, ed. N.J. Foss and S.Michailova. Oxford: Oxford University Press.

Grandori, A., M. Furlotti. 2006. “The Bearable Lightness of Inter-firm Strategic Alliances: Resource-based and Procedural Contracting." In Strategic Alliances: Governance and Contracts, ed. A. Ariño and J. Reuer. London: Palgrave.

Grandori A., Soda G. and G. Usai. 1999. "Rules as a Mode of Economic Governance.” In Regulation and Organization, ed. L.Engwall and G.Morgan. London: Routledge. Grossman, S.J. and O.D. Hart. 1986. "The Costs and Benefits of Ownership: A Theory of Vertical and Lateral Integration.” Journal of Political Economy 94(4): 691.

Hansmann, H. 1996. The Ownership of the Enterprise. Cambridge: Belknap Press.

Hart, O.D. 1988. "Incomplete Contracts and the Theory of the Firm." Journal of Law, Economics \& Organization 4(1): 119.

Hart O. and J. Moore .1990. "Property Rights and the Nature of the Firm." The Journal of Political Economy 8/6:1119-1158.

Hayek, von F.A. 1945. "The Use of Knowledge in Society.” American Economic Review 35(4): 519.

Henderson, R., Orsenigo, L. and G. P. Pisano. 1999. "The Pharmaceutical Industry and the Revolution in Molecular Biology: Interactions among Scientific, Institutional and 
Organizational Change.” In Sources of Industrial Leadership. Studies of Seven Industries, ed. D.C. Mowery, and R.R. Nelson. Cambridge: Cambridge University Press.

Hendrikse G. 2002. “Ownership Structure in Agrifood Chains:the Marketing Cooperative.” American Journal of Agricultural Economics 84(1): 104-119.

Kaplan, S.N. and P. Strömberg. 2003. "Financial Contracting Theory Meets the Real World: An Empirical Analysis of Venture Capital Contracts.” Review of Economic Studies 70(245): $281-315$

Klein, B. 2000. "The Role of Incomplete Contracts in Self-enforcing Relationships.” Revue d'Economie Industrielle (92): 67-80.

Lammers, C. 1993. “Interorganizational Democracy”. In Interdisciplinary Perspectives on Organization Studies, ed. S. Lindenberg and H.Schreuder, 323-337. Pergamon Press. Langlois R.N. 1986. "Rationality, Institutions and Explanation.” In Economics as a Process, ed. R. N. Langlois. Cambridge: Cambridge University Press.

Lerner, J. and R.P. Merges. 1998. "The Control of Technology Alliances: An Empirical Analysis of the Biotechnology Industry.” Journal of Industrial Economics 46(2):125-156.

Loasby, B.J. 1976. Choice, Complexity, and Ignorance. Cambridge: Cambridge University Press. Locke, E.A. 1996. "Motivation through Conscious Goal Setting." Applied and Preventive Psychology, 5(2):117-124.

Macaulay, S. 1963. "Non-contractual Relations in Business: A Preliminary Study.” American Sociological Review, 28(1): 55-67.

Macneil, I.R. 1978. "Contracts: Adjustment of Long-term Economic Relations under Classical, Neoclassical, and Relational Contract Law." Northwestern University Law Review 72: 854-905. 
McKelvey, M. and L. Orsenigo. 2004. "Pharmaceuticals as a Sectoral Innovation System.” In Sectoral Systems of Innovation, ed. F. Malerba. Cambridge: Cambridge University Press. Miller, G.J. 1992. Managerial Dilemmas: The Political Economy of Hierarchy. New York: Cambridge University Press.

Ouchi W.G. 1979. “A Conceptual Framework for Design of Organizational Control Mechanism.” Management Science 25:833-848.

Penrose, E. 1995. The Theory of the Growth of the Firm. Oxford: Oxford University Press. Raiffa, H. 1982. The Art and Science of Negotiation. Cambridge: Cambridge University Press.

Ring, P.S. and A. H. Van de Ven.1992. "Structuring Cooperative Relationships between Organizations.” Strategic Management Journal 13(7): 483-498.

Shackle G.L. 1972. Epistemics and economics. Cambridge: Cambridge University Press. Simon, H.A. 1960. The New Science of Management Decision. New York: Harper Row. Simon, H.A. 1976. "From Substantive to Procedural Rationality." In Method and Appraisal in Economics, ed. S.J. Latsis. Cambridge: Cambridge University Press.

Stinchcombe, A.L. 1985. "Contracts as Hierarchical Documents.” In. Organization Theory and Project Management, ed. A.L. Stinchcombe and C. Heimer. Oslo: Norwegian University Press.

Suchman, M.C. 1994. "On Advice of Counsel: Law Firms and Venture Capital Funds as Information Intermediaries in the Structuration of Silicon Valley." Doctoral Dissertation. Stanford University.

Tadelis, S. 2002. "Complexity, Flexibility, and the Make-or-Buy Decision." American Economic Review 92(2): 433-437.

Tirole J. 1999. “Incomplete Contracts: Where Do We Stand?” Econometrica 67/4: 741-781. 
Vanberg, V.J. 1994. Rules and Choice in Economics. London: Routledge.

Williamson, O.E. 1975. Markets and Hierarchies: Analysis and Antitrust. New York: Free Press.

Williamson, O.E. 1979. "Transaction-cost Economics: The Governance of Contractual

Relations.” Journal of Law \& Economics 22(2): 233-261.

Williamson O.E. and W.G. Ouchi. 1981 “The Markets and Hierarchies Program of Research:

Origins, Implication, Prospects.” In Perspectives on Organization Design and Behavior, ed. A.H. Van de Ven and W.F. Joyce. New York: Wiley.

Yin, R.K. 1984. Case Study Research. Beverly Hills, CA: Sage Publishing.

\footnotetext{
${ }^{\mathrm{i}}$ Implicitly, we are implying that actors engaged in innovation are able to adopt an extended version of heuristic rationality, capable of sound, logically correct, science-like discovery; rather than to be just 'limited' in their possibility of 'completely' scanning a computationally complex problem space, as assumed in standard bounded rationality models. A specific treatment of this issue is given in Grandori (1984, 2005b).

ii In fact, the identity of parties matters most in innovation partnerships; where contracting on actions is not feasible, all is about who are we associating with; and this cannot be defined only by means of rules of access (no more than we could define a rule for selecting a marriage partner).

iii In the highly refined Roman juridical tradition, from which most western juridical systems derive, the useful distinction between a 'contract of society' and a 'contract of exchange' was clear. It has been maintained in some Civil law systems, but it got lost in the Common Law juridical tradition.

iv This prediction does not exclude that associational contracts with such a profile are also found in non-innovative settings for other reasons. In particular, democratic, multi-party governance regimes can be justified as superior solutions whereas human capital investments are critical even though not knowledge intensive, such as in work cooperatives (Hart and Moore 1990; Hansman 1996; Grandori 1999; Hendrikse 2002)

${ }^{\mathrm{V}}$ The contracts analyzed and the complementary information have been provided by Recombinant Capital (Recap), a San Francisco Bay Area-based consulting firm specializing in biotechnology alliances, whose help is gratefully acknowledged.

${ }^{\text {vi }}$ The specification of royalty accounting provisions and of financial definitions in general, may occupy a considerable portion of technology alliance contracts. For example, in the agreement of alliance A, these provisions take up about a dozen pages.

vii Other causes of termination commonly provided for in alliance contracts are bankruptcy, breach of the contract, dissolution or winding up. These provisions, that are quite standardized across contracts, can be seen as pertaining to the 'risk planning' section of contracts (Macneil 1975) and will not be dealt with in this study that is designed rather to focus on the 'performance planning' aspects.

${ }^{\text {viii }}$ For instance, in alliance $C$ the client has a final say on technical matters only in the case that the JSC is unable to reach consensus and after the possibilities to reach an agreement through negotiation between senior executive officers have been exhausted.

${ }^{\text {ix }}$ For instance, in alliance D, $P \& G$ (the client) holds unfettered decision rights only with regards to the strategy and tactics of selling and commercializing marketed products, but not for development activities. Moreover, while P\&G is allowed to unilaterally terminate the agreement, that option can be triggered only by an unambiguous failure of the products to meet Success Criteria that have been set by the Joint Steering Committee beforehand.

${ }^{x}$ A similar arrangement can be seen in alliance $\mathrm{D}$, where conflict of interest about resources is defused by certain limitation of the powers of the JSC to amend the initial R\&D plan. In a similar vein, alliance C safeguards the R\&D
} 
firm by setting a floor to the minimum number of FTEs to be reimbursed by the client, despite all the possibilities granted to him to cast a deciding vote on many controversial issues.

${ }^{x i}$ Contingency clauses are also used occasionally as enforcement mechanisms. E.g.: in case of failure to exercise Diligent Effort to Commercialize in a country, all rights for the country revert to the other party [A].

xii. KGP is the international research project 'Knowledge, Governance and Projects: Configurations and Dynamics of the Project-based Economy' (2004-2007) coordinated by Anna Grandori, Crora-Bocconi University; partners: Patrick Cohendet (University of Strasbourg and Montreal), Mark Ebers (University of Colone), Gernot Grabher (University of Bonn), Peter Maskell (Copenhagen Business School), Andrea Prencipe (SPRU - University of Sussex and Università of Pescara); and funded by the Italian Ministry for Education, University and Research (MIUR) and by the collaborating universities. 